\author{
Organic and Medicinal Chemistry \\ International Journal \\ ISSN 2474-7610
}

\title{
A New Approach to Design Hydroxyapatite and Silk Fibroin Bone Substitutes
}

\author{
Daniela Vieira ${ }^{1,2 *}$, Dayane Dotto ${ }^{1}$, Eliana C da S Rigo ${ }^{1}$, Sheyla M C M Bicalho ${ }^{3}$ and Sergio A Yoshioka ${ }^{1}$ \\ ${ }^{1}$ Graduate Program in Bioengineering, University of São Paulo, Brazil \\ ${ }^{2}$ Experimental Surgery, Faculty of Medicine, McGill University, Canada \\ ${ }^{3}$ JHS Biomateriais, Brazil
}

Submission: October 13, 2020; Published: November 25, 2020

*Corresponding author: Daniela Vieira, Graduate Program in Bioengineering, University of São Paulo, São Carlos 13566-590, Brazil

\begin{abstract}
Biomaterials to regenerate bone have been gaining great visibility in tissue engineering. The design of a material like bone is a great challenge, especially when combining the ideal mechanical strength, porosity, and bioactivity. This work focused on the development of a new candidate for bone substitute combining hydroxyapatite (HAp) and silk fibroin (SF). The silk fibroin, obtained from the cocoons of the silkworm (Bombyx mori), was dissolved using a ternary solution of calcium, ethanol, and water. HAp was co-precipitated dropping phosphate solution (Na2HPO4) in SF at a constant stirring. The final composite, $75 \% \mathrm{HAp} / 25 \% \mathrm{SF}$, were framed using a hydraulic system varying the pressure to find the best candidate. Physical and chemical characterizations were evaluated, as well as the bioactivity and cytotoxicity. Results showed excellent chemical and physical properties, like the trabecular bone. The $75 \% \mathrm{HAp} / 25 \% \mathrm{SF}$ biocomposite was safe to $\mathrm{CHO}$ cells and presented great bioactivity being an alternative candidate to the bone regeneration field.
\end{abstract}

Keywords: Hydroxyapatite; Silk fibroin; Co-precipitation; Bone scaffold; Tissue engineering

\section{Introduction}

Tissue engineering is a promising strategy for the field of bone regeneration. Only in 2020, approximately 6.6 million of orthopedic surgeries were performed worldwide due to the bone fractures, disease, or malformation. As the world population grows at a fast rate, there is a huge need on developing substitutes able to mimic the structure and function of the original bone [13]. The current focus on bone substitute is on bioactive materials, where the material can interact to biological molecules and cells, and, simultaneously, regenerating the bone tissue. The ideal material for bone regeneration should present osteoconduction, osteoinduction and osteointegration; as well as good mechanical strength, porosity, and biocompatibility $[2,4,5]$.

Hydroxyapatite (HAp) has been attracting a lot of attention as bone substitute biomaterial because of high porosity and threedimensional porous structure, which provide optimal conditions for the growth and proliferation of cells. Furthermore, its porosity allows oxygen and nutrients diffusion, creating vascular integration. However, HAp is naturally fragile making it not suitable to be framed by itself $[2,3,5]$. To increase the mechanical properties of HAp different strategies have been applied, as such as the incorporation of natural polymers (collagen, chitosan, and silk fibroin). Silk fibroin (SF), has been widely used in the biomedical field due to excellent biocompatibility and mechanical properties, in addition, it presents excellent thermodynamic properties (degradation $>150^{\circ} \mathrm{C}$ ) when compared to the available biopolymers, such as collagen [6,7].

Current, there are several research combining HAp and SF in different proposals, such as gel, sponges, cements, etc. However, the current methodologies involve expensive and time-consuming techniques and cannot reach the perfect balance between mechanical strength and porosity [8]. Here we designed a simple and cost-effectiveness strategy able to create HAp/SF scaffolds with ideal porosity and mechanical strength.

\section{Materials and Methods}

All chemicals were obtained from Sigma. Silk fibroin solution was prepared following Ajisawa protocol [9]. Briefly, 5g of Bombyx mori silkworm cocoons (donated by Bratac, Brazil) were degummed for 30 minutes in a boiling $0.02 \mathrm{M}$ sodium carbonate solution to remove sericin. The degummed silk was rinsed 3 times in deionized water and dried overnight at $45^{\circ} \mathrm{C}$. The dried silk fibers were dissolved in a $0.1 \mathrm{M} \mathrm{CaCl}_{2} / 0.2 \mathrm{M}$ ethanol/0.8M $\mathrm{H}_{2} \mathrm{O}$ 
solution at $70^{\circ} \mathrm{C}$ for $4 \mathrm{~h}$. The final silk fibroin solution was filtered (MF-Millipore $^{\mathrm{TM}}$ MCE Membrane Filters - Sigma) to remove impurities. We designed a co-precipitation technique to prepare HAp/SF composites. Briefly, we prepared a solution containing $0.12 \mathrm{~mol}$ of $\mathrm{Na}_{2} \mathrm{HPO}_{4}$ in $150 \mathrm{~mL}$ of $0.5 \mathrm{M}$ Tris- $\mathrm{HCl}$ solution at $\mathrm{pH}$ 9.0. The concentration of phosphate was proportional to $\mathrm{Ca}$ concentration to obtain 1.67 ratio of $\mathrm{Ca} / \mathrm{P}$. The final solution was slowly dropped into the silk fibroin solution with intense mechanical stirring $(10,000 \mathrm{RPM})$ for 30 minutes. To obtain the best candidate, different ratios of HAp/SF were studied (65/35\%, 75/25\%, 85/15\% e 95/5\%). The best candidate was molded using a hydraulic system (Prensa MAXX - 3ton, Essence Dental) using a circular stainless frame $(\varnothing 9 \mathrm{~mm} \times 10 \mathrm{~mm})$ and dried at $60^{\circ} \mathrm{C}$ for $48 \mathrm{~h}$. Two different pressures (50 MPa and $100 \mathrm{MPa}$ ) were studied to get the desired mechanical resistance and porosity characteristic. Finally, the molded composite was washed in distillated water for $48 \mathrm{~h}$ (changing water every $4 \mathrm{~h}$ ) and dried at $60^{\circ} \mathrm{C}$ for $48 \mathrm{~h}$.

\section{Physical and chemical characterizations}

SEM images were obtained in a ZEISS LEO 440 (Cambridge, England) equipment with OXFORD detector (model 7060), operating with $20 \mathrm{kV}$ electron beam, 2.82A current and 200pA I probe. The samples were coated with carbon using Coating System BAL-TEC MED 020 (BAL-TEC, Liechtenstein). Pores size were measured from SEM images using ImageJ software. EDX was performed on Isis System Series 200 equipment, with SiLi Pentafet detector, ATW II ultra-thin window (ATW II) window, from $133 \mathrm{eV}$ to $5.9 \mathrm{keV}$, coupled to a LEO Electron Microscopy Ltd), using an Oxford Detector (Oxford Instruments Inc.). Thermogravimetric analyze (TGA) was performed from $25^{\circ} \mathrm{C}$ to $800^{\circ} \mathrm{C}$, in a synthetic air, using $10 \mathrm{mg}$ at heating rate of $10^{\circ} \mathrm{C} . \mathrm{min}-1$ (Q-50 model - TA Instruments). FTIR spectra were performed using A Shimadzu IRAffinity-1 spectrophotometer, with 64 scans and resolution of 4 $\mathrm{cm}^{-1}$, wave range from 400 to $4000 \mathrm{~cm}^{-1}$ on $\mathrm{KBr}$ tablets.

X-ray diffraction was applied to verify crystallinity using a Bruker D8 Discovery Instrument X-ray diffratometer (CuKa radiation, $2 \theta$ diffraction). Mechanical compression was performed using a TIME GROUP $30 \mathrm{KN}$ equipment, with load cells of 5-ton, speed of $0.5 \mathrm{~mm} /$ minute. The total porosity was calculated based on the Archimedes method (NBR ISO 5017:2015) [10]. Briefly, samples were dried at $60^{\circ} \mathrm{C}$ for $24 \mathrm{~h}$. After dried, samples were weighted and recorded as M1. Samples were then placed in a beaker containing ethanol. Deaeration cycles were applied to complete absorption of ethanol inside the samples. After complete ethanol immersion, the weight was measured and recorded as M2. Finally, the immersed sample was weighted and recorded (M3) using mechanical analytical balance. The $\%$ of liquid absorption (\%LA) was calculated using equation I and the \% of apparent porosity (\%AP) using equation II.

$$
\begin{aligned}
& \% L A=\frac{M 2-M 1}{M 2} \times 100 \\
& \% A P=\frac{M 2-M 1}{M 2-M 3} \times 100
\end{aligned}
$$

Micro computed tomography (micro-CT) was applied to observe the composite in 3D images, evaluating its volume, porosity, and pore connectivity. The samples were scanted in SkyScan 1172 Micro-CT equipment (SkyScan; Kontich, Belgium). The reconstruction of the images was performed using NRecon (Version 1.6.2.0; SkyScan). Ct-Vol software (SkyScan, August 2003, Aartselaar, Belgium) was used to calculate porosity and volume.

\section{In vitro analyses}

Cytotoxicity was performed in CHO cells using neutral red assay (ISO 10993-5 - Test for in vitro cytotoxicity) [11]. Phenol was used as a positive control (toxic) and alumina as a negative control (non-toxic). The bioactivity was evaluate based on the apatite formation using ISO 23317 protocol [12]. Briefly, samples were incubated in SBF solution at $36.5^{\circ} \mathrm{C}$ for 0,14 and 28 days. After incubated period, SEM was performed to verify visually the apatite formation.

\section{Results and Discussion}

\section{Physical and chemical characterizations}

The porosity, mechanical strength and ratio of calcium/ phosphate are essential parameters to analyze the performance of a bone substitute [13-15]. Here, to assure the best ratio of hydroxyapatite (HAp) and silk fibroin (SF), we pre-analyzed these parameters for different ceramic/polymer ratio after manually framed to find the best candidate for the study. We concluded that the $75 \% \mathrm{HAp} / 25 \% \mathrm{SF}$ presented more favorable performance when compared to other proportions investigated (Table 1 ). In this way, the hydraulic pressing procedure and others characterization were evaluated on $75 \% \mathrm{HAp} / 25 \%$ SF ratio.

Table 1: Pre-test to evaluate the best candidate for the study.

\begin{tabular}{|c|c|c|c|}
\hline Sample & Ca/P ratio & \% Liquid Absorption (g/g) & Compressive Strength (MPa) \\
\hline $65 \% \mathrm{HAp}+35 \% \mathrm{SF}$ & $1.89 \pm 0.01$ & $63.8 \pm 2.2$ & $0.25 \pm 0.11$ \\
\hline $75 \% \mathrm{HAp}+25 \% \mathrm{SF}$ & $1.67 \pm 0.15$ & $61.4 \pm 0.8$ & $0.36 \pm 0.01$ \\
\hline $85 \% \mathrm{HAp}+15 \% \mathrm{SF}$ & $2.23 \pm 0.23$ & $58.8 \pm 1.5$ & $0.11 \pm 0.05$ \\
\hline
\end{tabular}

The interconnection and distribution of pores are fundamental to allow cells adherence, proliferation, and differentiation. In addition, it provides paths to nutrients and oxygen flows, helping with the growth of the new tissue and blood vessels $[15,16]$. The SEM images in Figure 1 show the $75 \%$ HAp/25\%SF composite morphology. 


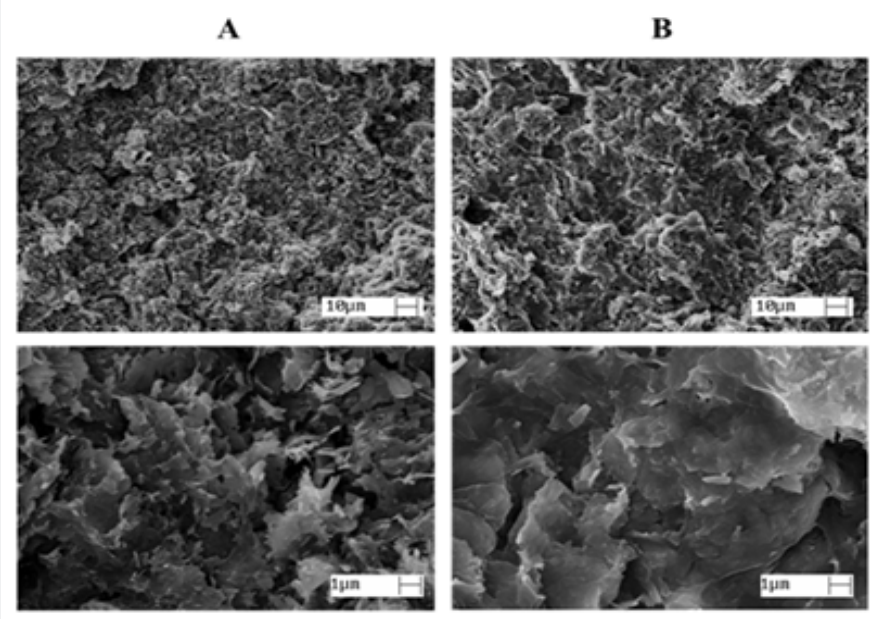

Figure 1: The interconnection and distribution of pores for 75\% HAp/25\%SF composites pressured at (A) $50 \mathrm{MPa}$ and (B) $100 \mathrm{MPa}$.

A similar pore distribution was observed for samples pressed at $50 \mathrm{MPa}$ and $100 \mathrm{MPa}$, presenting diameters between $1 \mu \mathrm{m}$ and $50 \mu \mathrm{m}$. The composite had a homogeneous and wellinterconnect structure. The co-precipitation procedure allowed a well bound between HAp and SF, especially due to the carbonyl group present in SF that binds to the $\mathrm{Ca}+2$, that forms carbonylcalcium complexes. When dropping the phosphate solution, P043- accumulated around the complex and initiated the nucleation of HAp. Due to the strong chemical interaction between the carbonyl groups and $\mathrm{Ca} 2+$, SF induced the self-organization and orientation of HAp crystals. Finally, HAp is cross-linked with the SF, forming this homogeneous network [17-19]. EDX analysis showed the $\mathrm{Ca} / \mathrm{P}$ ratio of 1.67, like the inorganic bone material [20] (Figure 2).

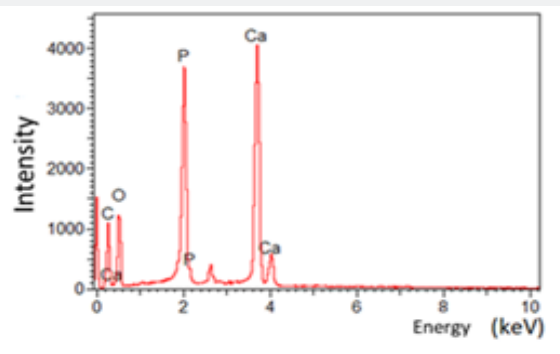

\begin{tabular}{l|c|c}
\hline Element & $\begin{array}{c}\text { Experimental } \\
\text { (\%) }\end{array}$ & Theory $^{*[20 \mid} \mathbf{( \% )}$ \\
$\mathrm{C}$ & 27.27 & 0 \\
$\mathrm{O}$ & 39.73 & 59.09 \\
$\mathrm{P}$ & 12.39 & 13.64 \\
$\mathrm{Ca}$ & 20.61 & 22.73 \\
$\mathrm{H}$ & $\mathrm{N} / \mathrm{A}$ & 4.54 \\
$\mathrm{CaP}$ & 1.67 & 1.67 \\
\hline
\end{tabular}

Figure 2: EDX analysis for $75 \% \mathrm{HAp} / 25 \% \mathrm{SF}$ composite.

The thermo behavior of $75 \% \mathrm{HAp} / 25 \% \mathrm{SF}$ is shown in Figure $3 \mathrm{~A}$. We observed the water evaporation between $25^{\circ} \mathrm{C}$ and $120^{\circ} \mathrm{C}$. The SF degradation started around $290^{\circ} \mathrm{C}$ when it is alone and shifted to $300^{\circ} \mathrm{C}$ when it is bound to HAp, indicating the strong link between SF and HAp [13,18,20,21]. The total weight loss was $35 \%$, where $5 \%$ was related to the water evaporation, showing that the organic/inorganic composition is approximately $70 / 30$, close to the desired ratio $75 / 25$. 


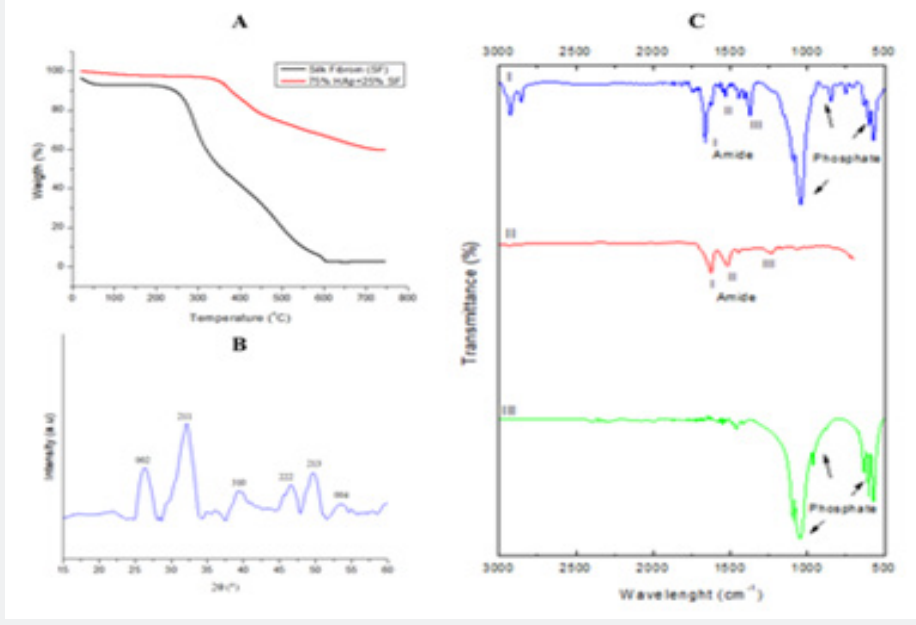

Figure 3: (A) TGA, (B) XRD and (C) FTIR of $75 \%$ HAp/25\% SF composite.

FTIR studies were applied to analyze the structure based on the functional groups. Figure 3B shows the spectra of the

i. $\quad 75 \% \mathrm{HAp} / 25 \% \mathrm{SF}$,

ii. silk fibroin and

iii. deproteinized bone (donated by biochemistry and biomaterials group of IQSC- USP/Brazil).

The absorption bands at 1098, 1041, 844, 601 and $568 \mathrm{~cm}^{-1}$ are related to PO4-3 present in HAp

(i). Similar bands were identified in the deproteinized bone (ii) because of the vibrations of phosphate ion [22-24]. The bands at 1658,1532 is $1368 \mathrm{~cm}^{-1}$ are characteristics of vibrations of the I, II, III amide groups, respectively, present in silk fibroin (i and ii). It is important to note a more intense peak for $75 \% \mathrm{HAp}+25 \% \mathrm{FS}$ compared to the silk fibroin, indicating an increase in $\beta$ conformation due to the link with HAp [25-27].

XRD spectrum for $75 \% \mathrm{HAp} / 25 \% \mathrm{SF}$ is shown in Figure 3C. The crystallographic plans at (002), (211), (310), (222), (213) and (004) represent the characteristic pattern of HAp, showing no formation of any different calcium phosphate. However, these peaks are broaded and overlapped (evidenced in the 211 plan) demonstrating the presence of amorphous phase in HAp precipitated, very similar to biological apatite present in natural bone $[28,29]$. The HAp crystallinity is directly affected by the temperature; low temperature process creates broaded peaks and amorphous phases, while at higher temperatures, the peaks are sharper, indicating an increase in the crystallinity. Similar results were found in different studies with HAp/SF composites. Different works observed the overlapping at (211) plan, resulting in low crystallinity and more amorphous phase compared to HAp synthetic $[13,17,18,30]$.

The $\%$ of porosity and $\%$ of liquid absorption of 75\%HAp / 25\% SF is described in Table 2. The ideal porosity of a bone substitute must be greater than $30 \%$ to allow interconnection and provide sufficient opportunities for cell migration and proliferation $[5,14,15]$. Through the liquid absorption capacity, it is possible to preview if the material will be able to guarantee the diffusion process for cells, nutrients, and oxygen $[14,15]$. Similar $\%$ of apparent porosity and \% of liquid absorption were found for samples pressed at 50MPa and $100 \mathrm{MPa}$. Samples pressed at $100 \mathrm{MPa}$ presented an increase of $\sim 5 \%$ for these parameters compared to samples pressed at $50 \mathrm{MPa}$. Both samples presented great structure to allow cells adherence and growth, with porosity above $50 \%$.

Table 2: The porosity of $75 \% \mathrm{HAp} / 25 \% \mathrm{SF}$ shows a great ability to allow the flow of cells, nutrients, and oxygen.

\begin{tabular}{|c|c|c|}
\hline $\mathbf{7 5} \% \mathbf{H A p} / \mathbf{2 5 \% S F}$ & Apparent Porosity (\%) & Liquid Absorption (\%) \\
\hline $50 \mathrm{MPa}$ & $52.23 \pm 2.15$ & $34.31 \pm 2.51$ \\
\hline $100 \mathrm{MPa}$ & $56.83 \pm 2.20$ & $40.89 \pm 5.16$ \\
\hline
\end{tabular}

One of the greatest challenges on the development of bone substitutes is combine the ideal porosity and mechanical resistance. A structure with the ideal porosity often sacrifices the mechanical properties and vice-versa. Mechanical compression tests were performed to evaluate the stress behavior of $75 \%$
HAp/ 25\% SF pressed at 50 and $100 \mathrm{MPa}$ (Figure 4). The samples pressed at $50 \mathrm{MPa}$ and $100 \mathrm{MPa}$ showed compressive stress of $2.62 \pm 0.74$ and $2.13 \pm 0.16 \mathrm{MPa}$, respectively, like the trabecular bone. Our composite demonstrated sufficient strength to ensure the early stabilization right after implant, supporting the first 
compressive stress. Usually, the scaffolds for bone substitutes are made using hydraulic pressing or freeze-drying methodology. The first process guarantees a higher compressive strength, sacrificing the porosity, while the second one, ensure a good porosity but decrease its strength. Different works involving HAp and SF observed a significant increase in the mechanical strength when $\mathrm{SF}$ was incorporated to the material $[13,15,31-33]$.

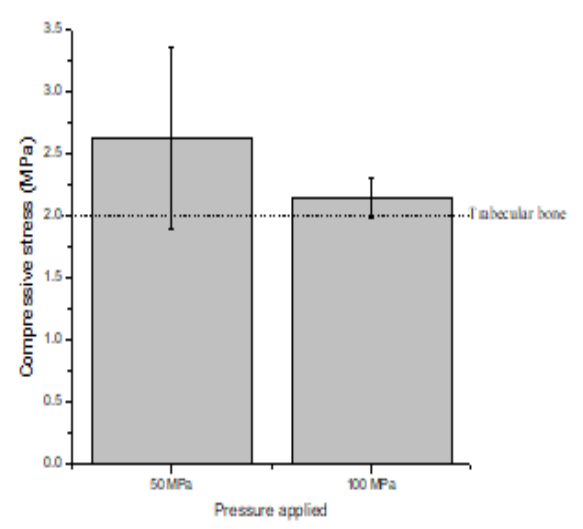

Figure 4: Compressive strength response in function of pressure applied, 50 and $100 \mathrm{MPa}$, respectively. The $75 \% \mathrm{HAp} / 25 \% \mathrm{SF}$ composite demonstrated similar behavior to trabecular bone.

Another way to verify the interconnection of pores could be applying images techniques such as micro computed tomography (micro-CT). Figure 5 shows 3D images of $75 \% \mathrm{HAp} / 25 \% \mathrm{SF}$ composite pressed at (a) $50 \mathrm{MPa}$ and (b) 100MPa. The complete analysis is in Supporting information Table 3. Here, according to the analyses carried out by SEM, we could observe porous from $1 \mu \mathrm{m}$ to $50 \mu \mathrm{m}$, where most pores are $\sim 35 \mu \mathrm{m}$ but not exceeding $50 \mu \mathrm{m}$. This pore size distribution allows the flow of osteocytes, osteoclasts, and the growth of blood vessels.
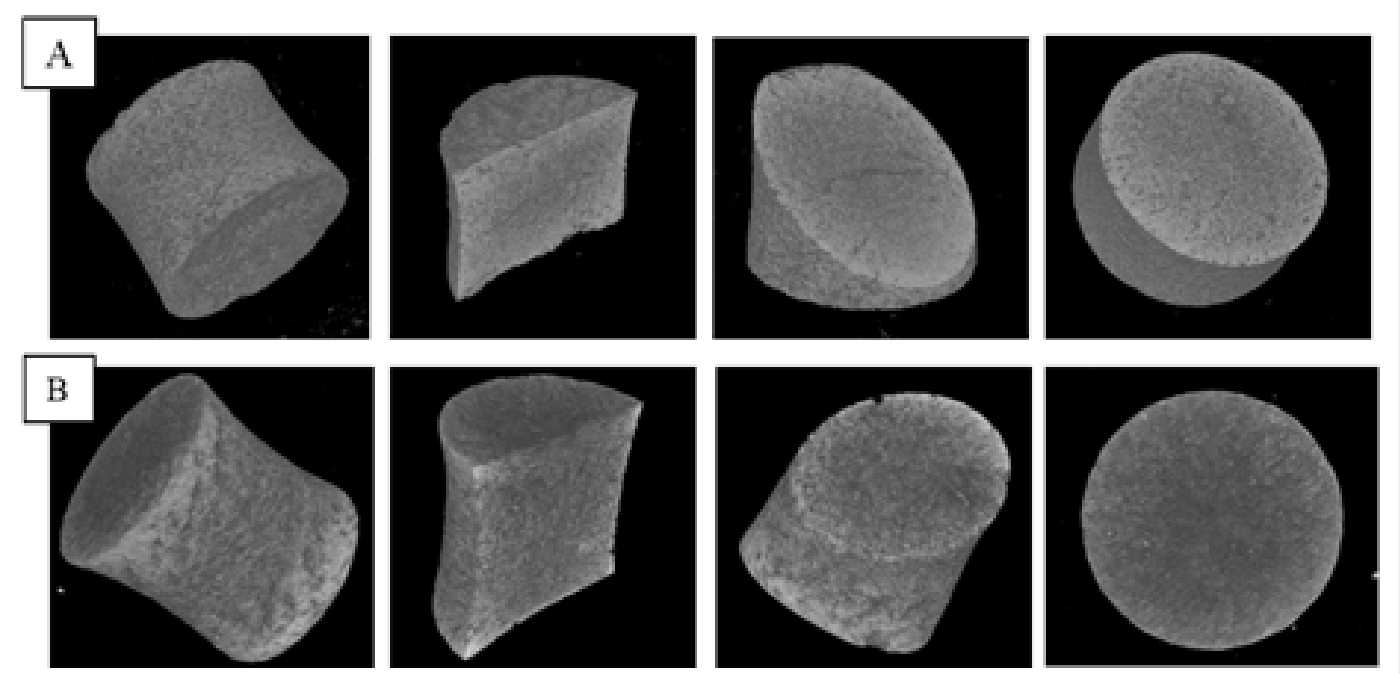

Figure 5: Micro-CT 3D images showing a homogenous morphology for 75\%HAp/25\%SF pressed at (A) 50 MPa and (B) 100 MPA.

Table 3: CTvol analyses for $75 \% \mathrm{HAp} / 25 \% \mathrm{SF}$ composite pressed at $50 \mathrm{MPa}$ and $100 \mathrm{MPa}$

\begin{tabular}{|c|c|c|}
\hline $\mathbf{( 7 5} \% \mathbf{H A p} / \mathbf{2 5 \% S F )}$ & $\mathbf{5 0} \mathbf{~ M P a}$ & $\mathbf{1 0 0} \mathbf{M P a}$ \\
\hline Total volume $\left(\mathrm{mm}^{3}\right)$ & 404,12 & 570,45 \\
\hline Filled volume $\left(\mathrm{mm}^{3}\right)$ & 368,19 & 542,32 \\
\hline Porosity - closed porous (\%) & 8,89 & 4,93 \\
\hline
\end{tabular}




\section{In vitro analyses}

The cytotoxicity assay is the first step to prove the biocompatibility of a new bone substitute. An ideal response should demonstrate cell viability of $70 \%$ or more [11,34]. In Figure 6 is demonstrated the \% of cell viability for $75 \% \mathrm{HAp} /$ $25 \% \mathrm{SF}$, pressed at $50 \mathrm{MPa}$ and $100 \mathrm{MPa}$. Alumina was used as a negative control (nontoxic) and phenol as a positive control (toxic). Our composite showed similar behavior to the negative control (Alumina), showing \% of cell viability above $80 \%$ and no toxicity for $\mathrm{CHO}$ cells. We only found toxicity in the positive control (phenol), as was expected. To investigate the bioactivity of our composite, we analyzed the ability to form apatite, a thin layer rich in $\mathrm{Ca}$ and $\mathrm{P}$, on the scaffold surface $[12,15]$. Biomineralization of apatite on the surface of bioactive scaffolds simulates the real reaction between the implanted material and the plasma and other biofluids [35,36]. SEM images (at day 0,14 and 28) for the $75 \% \mathrm{HAp} / 25 \% \mathrm{SF}$ pressed at 50MPa are demonstrated in Figure 7.

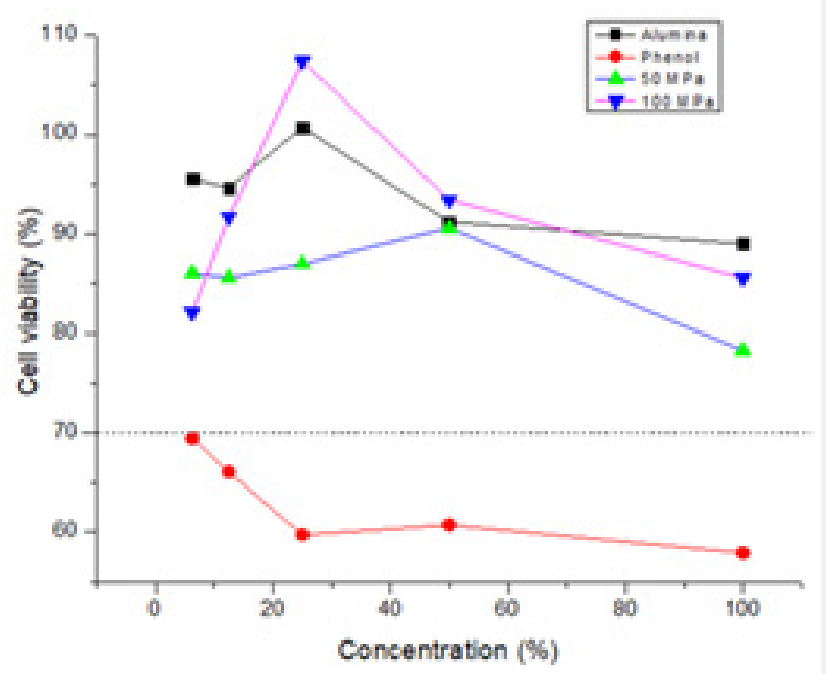

Figure 6: $\%$ of cell viability in contact to $75 \% \mathrm{HAp} / 25 \% \mathrm{SF}$ composite, alumina (negative control) and phenol (positive control).

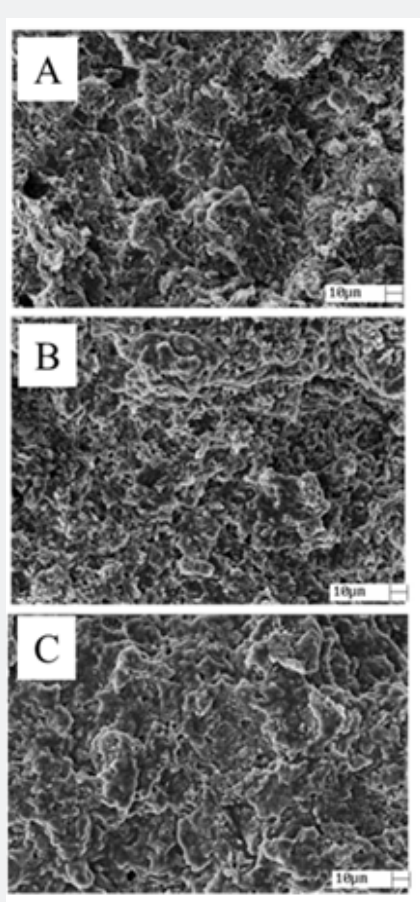

Figure 7: Bioactivity of $75 \% \mathrm{HAp} / 25 \% \mathrm{SF}$ composite showing the apatite growth on scaffold surface at (A) day 0 , (B) day 14 and (C) day 28. 
Clearly, we can see changes in the morphology at day 14 and 28. In 14 days it is possible to observe a thin layer of apatite growing on the scaffold surface, and more evident at day 28 . This result showed the higher bioactivity of $75 \% \mathrm{HAp} / 25 \% \mathrm{SF}$ composite to assist the integration of the implanted material, the new bone and the host tissue when simulating the body environment (SBF solution at $37^{\circ} \mathrm{C}$ and $\mathrm{pH} 7.4$ ).

\section{Conclusion}

We successful developed a new approach to co-precipitate HAp and SF forming a well homogeneous composite. We studied two different pressures to assemble the scaffold, but no significant differences were found, showing similar behavior for samples framed at $50 \mathrm{MPa}$ and $100 \mathrm{MPa}$. The chemical and physical characterizations demonstrated an ideal set of characteristics, such as porosity and mechanical strength. In addition, the final composite presented amorphous structure and inorganic/organic ratio like the trabecular bone. Our results showed an interconnected porous structure allowing the cells, nutrients, and oxygen flows. The designed co-precipitation method is sustainable, simple and cost-effectiveness, without the need of high temperatures, and aggregates values to the discarded silkworm cocoon.

\section{References}

1. B B Mandal, A Grinberg, E S Gil, B Panilaitis, D L Kaplan (2012) Highstrength silk protein scaffolds for bone repair. Proc Natl Acad Sci 109: 7699 .

2. S L McNamara, J Rnjak Kovacina, D F Schmidt, T J Lo, D L Kaplan (2014) Silk as a biocohesive sacrificial binder in the fabrication of hydroxyapatite load bearing scaffolds. Biomaterials 35: 6941.

3. J Melke, S Midha, S Ghosh, K Ito, S Hofmann (2016) Silk fibroin as biomaterial for bone tissue engineering. Acta Biomater 31: 1-16.

4. M M Stevens (2008) Biomaterials for bone tissue engineering. Mater Today 11: 18-25.

5. S Chun, D Yang, S Kim (2012) Comparison study of porous calcium phosphate blocks prepared by piston and screw type extruders for bone scaffold. Tissue Eng Regen Med 9: 51.

6. F Judas, P Palma, R I Falacho, H Figueiredo (2012) Structure and dynamics of bone tissue 1-51.

7. J Jiang, W Hao, Y Li, J Yao, Z Shao, H Li, et al. (2013) Hydroxyapatite/ regenerated silk fibroin scaffold-enhanced osteoinductivity and osteoconductivity of bone marrow-derived mesenchymal stromal cells. Biotechnol Lett 35: 657-661.

8. D N Rockwood, R C Preda, T Yücel, X Wang, M L Lovett, et al. (2011) Materials fabrication from Bombyx mori silk fibroin. Nat Protoc 6: 1612.

9. A Ajisawa (2001) Dissolution of silk fibroin with calciumchloride/ ethanol aqueous solution [1998]. J Sericultural Sci Jpn 67: 91.

10. ABNT Catalogo 5017.

11. R F Wallin, E F Arscott (1998) Med Device Diagn Ind 20: 96.

12. ABNT Catalogo 23317.

13. L Liu, J Liu, M Wang, S Min, Y Cai, et al. (2008) Preparation and characterization of nano-hydroxyapatite/silk fibroin porous scaffolds. Biomater Sci Polym 19: 325.
14. H J Park, O J Lee, M C Lee, B M Moon, H W Ju, et al. (2015) Fabrication of 3D porous silk scaffolds by particulate (salt/sucrose) leaching for bone tissue reconstruction. Int J Biol Macromol 78: 215-223.

15. A Teimouri, M Azadi, R Emadi, J Lari, A N Chermahini (2015) $\beta$-Chitin/ gelatin/nanohydroxyapatite composite scaffold prepared through freeze-drying method for tissue engineering applications. Polym Degrad Stab 121: 18.

16. S Alonso Sierra, R Velázquez Castillo, B Millán Malo, R Nava, L Bucio (2017) Interconnected porosity analysis by 3D X-ray microtomography and mechanical behavior of biomimetic organic-inorganic composite materials. Mater Sci Eng 80: 45.

17. L Wang, R Nemoto, M Senna (2004) Changes in microstructure and physico-chemical properties of hydroxyapatite-silk fibroin nanocomposite with varying silk fibroin content. J Eur Ceram Soc 24: 2707.

18. C Fan, J Li, G Xu, H He, X Ye, et al. (2010) Facile fabrication of nanohydroxyapatite/silk fibroin composite via a simplified coprecipitation route. J Mater Sci 45: 5814-5819.

19. N A Zakharov, L I Demina, A D Aliev, M R Kiselev, V V Matveev, et al. (2017) Synthesis and properties of calcium hydroxyapatite/silk fibroin organomineral composites. Inorg Mater 53: 333.

20. C Du, J Jin, Y Li, X Kong, K Wei, et al. (2009) Novel silk fibroin/ hydroxyapatite composite films: Structure and properties. Mater Sci Eng C 29: 62-68.

21. H Zhang, J Magoshi, M Becker, J Y Chen, R Matsunaga (2002) Thermal properties of Bombyx mori silk fibers. J Appl Polym Sci 86: 1817.

22. A Rapacz Kmita, C Paluszkiewicz, A Ślósarczyk, Z Paszkiewicz (2005) FTIR and XRD investigations on the thermal stability of hydroxyapatite during hot pressing and pressureless sintering processes. J Mol Struct 744: 653.

23. A Ślósarczyk, Z Paszkiewicz, C Paluszkiewicz (2005) FTIR and XRD evaluation of carbonated hydroxyapatite powders synthesized by wet methods. J Mol Struct 744: 657.

24. I Mobasherpour, M S Heshajin, A Kazemzadeh, M Zakeri (2007) Synthesis of nanocrystalline hydroxyapatite by using precipitation method. J Alloys Compd 430: 330.

25. X Chen, D P Knight, Z Shao, F Vollrath (2001) Regenerated Bombyx silk solutions studied with rheometry and FTIR. Polymer 42: 09969-09974.

26. S Hofmann, C W P Foo, F Rossetti, M Textor, G Vunjak Novakovic, et al. (2006) Silk fibroin as an organic polymer for controlled drug delivery. J Controlled Release 111: 219.

27. R Nazarov, H J Jin, D L Kaplan (2004) Porous 3-D scaffolds from regenerated silk fibroin. Biomacromolecules 5: 718-726.

28. S Koutsopoulos (2002) Synthesis and characterization of hydroxyapatite crystals: A review study on the analytical methods. J Biomed Mater Res Off J Soc Biomater Jpn Soc Biomater Aust Soc Biomater Korean Soc Biomater 62: 600.

29. R K Brundavanam, G E J Poinern, D Fawcett (2013) Synthesis of a bone like composite material derived from waste pearl oyster shells for potential bone tissue bioengineering applications. Am J Mater Sci 3: 84.

30. R Murugan, S Ramakrishna (2004) Bioresorbable composite bone paste using polysaccharide based nano hydroxyapatite. Biomaterials 25: 3829.

31. E S Gil, J A Kluge, D N Rockwood, R Rajkhowa, L Wang, et al. (2011) Mechanical improvements to reinforced porous silk scaffolds J Biomed Mater Res A 99: 16 
32.X N Qi, Z L Mou, J Zhang, Z Q Zhang (2013) Journal of biomedical materials research. Part A. J Biomed Mater Res Part Off J Soc Biomater Jpn Soc Biomater Aust Soc Biomater Korean Soc Biomater.

33. E Charriere, J Lemaitre, P (2003) Zysset Hydroxyapatite cement scaffolds with controlled macroporosity: fabrication protocol and mechanical properties Biomaterials 24: 809.

34. S O Rogero, A B Lugão, T I Ikeda, Á S Cruz (2003) Teste in vitro de citotoxicidade: estudo comparativo entre duas metodologias. Mater Res 6: 317.

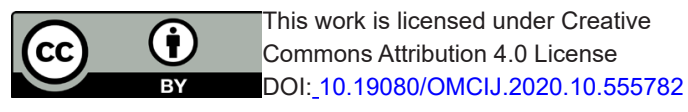

35. H M Kim, T Himeno, M Kawashita, T Kokubo, T Nakamura (2004) The mechanism of biomineralization of bone-like apatite on synthetic hydroxyapatite: an in vitro assessment. J R Soc Interface 1: 17.

36. T Kokubo, H Takadama (2006) How useful is SBF in predicting in vivo bone bioactivity? Biomaterials 27: 2907.

\begin{tabular}{|l|}
\hline \multicolumn{1}{|c|}{ Your next submission with Juniper Publishers } \\
will reach you the below assets \\
- Quality Editorial service \\
- Swift Peer Review \\
- Reprints availability \\
- E-prints Service \\
- Manuscript Podcast for convenient understanding \\
- Global attai nment for your research \\
- Manuscript accessibility in different formats \\
( Pdf, E-pub, Full Text, Audio) \\
- Unceasing customer service \\
Track the below URL for one-step submission \\
https://juniperpublishers.com/online-submission.php
\end{tabular}

